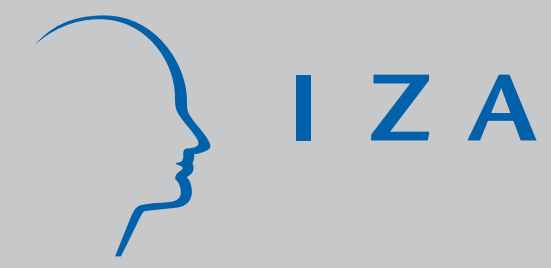

IZA DP No. 7952

Moving Ahead by Thinking Backwards:

Cognitive Skills, Personality, and Economic

Preferences in Collegiate Success

Stephen V. Burks

Connor Lewis

Paul Kivi

Amanda Wiener
Jon E. Anderson

Lorenz Götte

Colin DeYoung

Aldo Rustichini

February 2014 


\title{
Moving Ahead by Thinking Backwards: Cognitive Skills, Personality, and Economic Preferences in Collegiate Success
}

\author{
Stephen V. Burks \\ University of Minnesota, Morris, \\ IZA and CeDEx, University of Nottingham
}

Connor Lewis

University of Minnesota, Morris

Amanda Wiener

University of Minnesota, Morris

\author{
Paul Kivi \\ University of Minnesota, Morris
}

\author{
Jon E. Anderson \\ University of Minnesota, Morris
}

Discussion Paper No. 7952

February 2014

IZA

P.O. Box 7240

53072 Bonn

Germany

Phone: +49-228-3894-0

Fax: +49-228-3894-180

E-mail: iza@iza.org

\begin{abstract}
Any opinions expressed here are those of the author(s) and not those of IZA. Research published in this series may include views on policy, but the institute itself takes no institutional policy positions. The IZA research network is committed to the IZA Guiding Principles of Research Integrity.

The Institute for the Study of Labor (IZA) in Bonn is a local and virtual international research center and a place of communication between science, politics and business. IZA is an independent nonprofit organization supported by Deutsche Post Foundation. The center is associated with the University of Bonn and offers a stimulating research environment through its international network, workshops and conferences, data service, project support, research visits and doctoral program. IZA engages in (i) original and internationally competitive research in all fields of labor economics, (ii) development of policy concepts, and (iii) dissemination of research results and concepts to the interested public.
\end{abstract}

IZA Discussion Papers often represent preliminary work and are circulated to encourage discussion. Citation of such a paper should account for its provisional character. A revised version may be available directly from the author. 
IZA Discussion Paper No. 7952

February 2014

\title{
ABSTRACT \\ Moving Ahead by Thinking Backwards: Cognitive Skills, Personality, and Economic Preferences in Collegiate Success
}

\begin{abstract}
We collected personality (Big Five) and demographic characteristics, and ran incentivized experiments measuring cognitive skills (non-verbal IQ, numeracy, backward induction/ planning), and economic (time, risk) preferences, with 100 students at a small public undergraduate liberal arts college in the Midwestern US as part of a larger study that collected the same measures from 1,065 trainee truckers. Using standardized (z-score) versions of our variables we analyze their relative power to predict (1) timely graduation (four years or less), (2) graduation in six years or less, and (3) final GPA. The proactive aspect of Conscientious (but not the inhibitive one) has a large and robust positive effect on all three outcomes, and Agreeableness has a robust negative effect on both graduation outcomes, but not on GPA. Economic time preferences predict graduation in four years, and GPA. Cognitive skill measures predict as expected if entered individually in a multivariate model, but when all variables compete it is only our backward induction measure ("Hit15") that weakly predicts graduation in four years, and strongly predicts graduation in six years. Trainee truckers work in a different vocational setting and their results are appropriately different, but there is a common element: Hit15 also predicts their job success (completing a one year employment contract that makes training free). We interpret Hit15 as capturing a specific part of the cognitive skills required for self-management in non-routine settings - thinking backward from future goals to make the best current choice - that is not well measured by existing instruments, and suggest this deserves further scientific and institutional scrutiny.
\end{abstract}

JEL Classification: D03, 121, C99

Keywords: graduation, Big Five, cognitive skill, backward induction, economic preferences, GPA

Corresponding author:

Stephen V. Burks

University of Minnesota, Morris

Division of Social Sciences

600 East 4th Street

Morris, MN 56267-2134

USA

E-mail: svburks@morris.umn.edu 


\section{Introduction ${ }^{1}$}

\subsection{Human capital investment and student success in college}

In modern societies the formal educational system is the central institution through which investments in human capital - the productive capacity, in the broad sense, possessed by individual citizens - are made. Post-secondary education, while not compulsory, is required for success in a growing number of occupations, and a conventional economic analysis suggests that rational individuals should not start the process of investing in an educational program unless they have already judged the benefits to be worth the costs, and intend to complete the studies they have started. ${ }^{2}$ However, there has been concern over the dropout rates from post-secondary educational programs in the U.S. for some time (Horn, 2013; National Center for Higher Education Management Systems, 2010). For instance, the average year-to-year retention rate across all US institutions of higher education is approximately $75 \%$, and the average graduation rate for completing a four-year degree in four years is between 35 to $50 \%$, while a significant fraction of those starting a four-year degree never complete it (Adams, 2011; Leonhardt, 2005). Since failing to complete a degree affects a student's economic prospects while often leaving significant indebtedness, this empirical context has led economists to look at collegiate success through a broader lens than that provided by simple models of rational choice, and to consider what individual characteristics predict student success.

\subsection{A behavioral analysis of student success in college with a comparison to vocational success among truckers}

In the present paper we examine three measures of college success among a sample of 100 students from a four-year US college, the University of Minnesota, Morris (UMM), from a

\footnotetext{
${ }^{1}$ The authors benefitted from comments received at a seminar at the Centre for Decision Research and Experimental Economics (CeDEx) at the University of Nottingham, and at the Workshop on Self-control, Self-regulation, and Education at Århus University, Århus, Denmark. The authors gratefully acknowledge financial support for the Truckers and Turnover Project from the John D. and Catherine T. MacArthur Foundation's Research Network on the Nature and Origin of Preferences, the Alfred P. Sloan Foundation, the Trucking Industry Program at the Georgia Institute of Technology, and the University of Minnesota, Morris, and both financial and in-kind support from the cooperating motor carrier. The views expressed are those of the authors, and do not necessarily reflect the views of any of the supporting institutions.

${ }^{2}$ For a more nuanced view, see Stratton et al. (2008)
} 
broader, behavioral economic perspective. In spring, 2007, as part of a larger project, we collected data from our student subjects on cognitive skills (non-verbal IQ, numeracy, a "backward induction" measure of planning ability), personality (the Big Five), demographics, and economic (time, risk) preferences. We collected follow-up data in 2013 when we could assess three indicators of success: final cumulative grade point average (GPA), and whether students had graduated in four years (the standard time), in six years (a second standard evaluation criterion for institutional success), or not at all while under observation. Because the existing literature has primarily analyzed predictors of grades we first discuss GPA, but our focus is especially on graduation outcomes, as existing work on these important outcomes among college students is limited.

We find that the proactive aspect of the personality trait of Conscientiousness (but not its inhibitive one) strongly predicts final cumulative GPA. All of our cognitive skill measures predict GPA with varying degrees of robustness when entered singly in a multivariate model, but when all variables compete to predict GPA, no cognitive skill measure remains significant. In addition, one of our economic measures of time preferences (long term discounting in a quasihyperbolic discounting framework) predicts GPA. The Conscientiousness finding is consistent with the existing literature, though our specification of the proactive aspect is unique, as far as we know.

Turning to graduation, controlling for demographic factors, we find that the proactive aspect of the personality trait Conscientiousness (but not its inhibitive one) is robustly and positively related to finishing on time and also to finishing at all, while the personality trait Agreeableness is negatively related to both outcomes. Our conventional cognitive skill measures, IQ and numeracy, again predict as expected when entered singly in a multivariate model, but are not significant in the full model. We also find evidence that our economic measures of time preferences are positively related to finishing on time, but are not related to finishing at all.

Perhaps most distinctive are the results for our unconventional cognitive skill measure, the backward induction task ("Hit15"). This task requires subjects to think backwards from a simple numerical goal to determine the best current action when playing a game against the computer, which we interpret as a measure of planning or self-organizational ability (Gneezy et al., 2010). We find that while this planning measure adds modest incremental predictive power for graduating on time, it adds a large and statistically significant amount of predictive power for 
graduating in six years (i.e. at all), beyond that provided by personality characteristics and our more standard cognitive skill measures. In fact, comparing standardized effect sizes in regressions containing both variables, our planning measure is larger than non-verbal IQ, and of greater statistical significance, in its predictive power for graduation in six years.

Could this finding be specific to our subject pool? We think not. Because our student study is part of a larger project, we are able to compare the predictive power of Hit 15 for student success to its predictive power for job success among 1,065 trainees truck drivers who were undergoing vocational training at the time of data collection, a setting in which Hit15 also proved unexpectedly useful (Burks et al., 2009). After reviewing the trucker findings, which come from a quite distinct educational setting and subject pool, we suggest that the common thread is the value for both students and truckers of the ability to reason backwards to the best current action from changing and sometimes uncertain future goals and constraints. If this interpretation is correct it highlights the importance of preparation, support, and remedial training in selfmanagement for students as an institutional strategy for increasing college graduation rates, and it also suggests that this component of cognitive skill deserves more scientific attention.

\subsection{The structure of the paper}

The balance of the paper is structured as follows. First, we describe the location of the host institution for the study, UMM, in the higher education industry in the U.S., in order to locate our subjects in the larger reference pool of U.S. university students. Second, we review some highlights of the relevant literature that report findings on the relationship between subject characteristics we measure and student success. Third, we discuss the design of the data collection. Fourth, we provide a short descriptive overview of the characteristics of the subjects, grouped by graduation success categories. Fifth, we report the results of a series of logit regression models that explore the predictive power of our measures for student success when we control for more than one characteristic. The final section summarizes our results and discusses their limitations and their implications.

\section{Who are our subjects?}

Much work by experimental economists and psychologists is based upon subjects drawn from the ranks of students at the colleges at which the investigators teach. This naturally raises 
the question of the generalizability of the findings to subject pools that are culturally, socially, or demographically different. This issue has been recently addressed in Henrich et al. (2010), who point out that the degree of concern depends on the topic of the empirical investigation. Happily, in an analysis of college student success college students are exactly the right population.

However, in order to later assess the generalizability of our findings we must still locate our subjects in a large and diverse higher education system in the U.S.

\subsection{A mass higher educational system}

The higher education system in the United States - as of 2012 - consists of 4,599 degree granting post-secondary institutions (Snyder and Dillow, 2013). Unlike some European educational systems, which have traditionally separated students headed for vocational training from those going to university relatively early, the goal of the US educational system is for everyone who completes the first 12 compulsory years of primary and secondary schooling to have the opportunity for some level of post-secondary education. ${ }^{3}$ Approximately 2,600 of these institutions offer a full four-year Bachelor's level program, or more. In the fall of 2012, 21.3 million students $(6.8 \%$ of the population) were enrolled in post-secondary institutions around the United States, with 15.3 million attending public colleges or universities. Using the total population of the United States in 2012 as the reference, completion rates are as follows: 14.6\% attended some college, but never attained a degree, 6.8\% received a (two year) Associate's degree, $13.8 \%$ have a (four year) Bachelor's degree, and $7.3 \%$ have a professional or graduate degree (requiring one to several years further work after the Bachelors' degree) (Snyder and Dillow, 2013). Thus, $43.5 \%$ of the population has as least some post-secondary experience, and $21.1 \%$ of the population has at least a four-year degree. ${ }^{4}$

\subsection{The source of our subjects: University of Minnesota, Morris (UMM)}

Given the broadly-based character of the US higher educational system, institutions vary in the degrees offered and their level of student selectivity, and this is true of publicly-funded

\footnotetext{
${ }^{3}$ A consequence of this is that approximately 1,700 post-secondary institutions offer less than the standard fouryear Bachelor's (also called Baccalaureate) level college credential (Snyder and Dillow, 2013), and while many of the programs offered by these institutions prepare students to complete a four-year program elsewhere, many others cover topics that would be part of non-collegiate vocational training in some European countries.

${ }^{4}$ In recent years European countries have increased the proportion of students undertaking post-secondary education, so that today the U.S. is $10^{\text {th }}$ among the most developed countries in the percentage of young adults (ages 25-35) who have at least a two-year college degree (National Center for Higher Education Management Systems, 2010).
} 
institutions such as the University of Minnesota, Morris as well as privately operated colleges and universities. The Carnegie Foundation for the Advancement of Teaching provides a widelyused classification system for US institutions of higher education that was last updated in 2010. According to this system, UMM is classified as follows: arts and science focus, exclusively undergraduate offering a Baccalaureate degree, full-time four-year, more selective, lower transfer-in, small, and highly residential (Carnegie Foundation for the Advancement of Teaching, 2010). UMM is located on the prairie in west central Minnesota, with an enrollment of 1,900 students, and a curricular design similar to that of many private liberal arts colleges. ${ }^{5}$

Although UMM is in the top "more selective" category according to Carnegie, the Carnegie classification system has only three levels of selectivity, and there is significant variation within its "more selective" category. A finer-grained classification comes from ACT, Inc. (formerly “American College Testing, Inc."), which publishes one of the standardized high school achievement and college admissions test (also known as the "ACT"). ${ }^{6}$ As part of its market research ACT regularly issues a report on the selectivity of approximately 1,800 institutions that provide it with survey responses. Table 1 shows the ranking system that results (ACT, 2013), according to which UMM is in the second of five categories, with average ACT scores for its entering freshmen in the 21-26 category (typically the actual mean is about 25).

\section{$<$ INSERT Table 1 ABOUT HERE $>$}

Graduation rates vary significantly across publicly funded institutions of higher learning in Minnesota. The four-year and six year graduation rates across the eleven public four-year campuses in the state are shown in Figure 1 (based on data from the web site of Chronicle of Higher Education, 2014). UMM is among the highest in both measures. The observed differences to some degree reflect the variations in educational mission and selectivity

\section{$<$ INSERT Figure 1 ABOUT HERE $>$}

across the institutions and campuses. The overall rate for graduation in four years at all Minnesota colleges and universities (including privately operated ones) is $30.6 \%$ (which rises to

\footnotetext{
${ }^{5}$ A classic liberal arts college educates students in the historically central areas of the fine arts and humanities, the social sciences, and the natural sciences and mathematics, requiring each student to be exposed to introductory courses across all the main curricular areas, as well as then having them then focus on one or more majors that fall within these areas. Think of this as a recipe for acquiring general human capital and the basis for good citizenship, with a specialization in the major that can lead either to more advanced academic or vocational/professional study.

${ }^{6}$ The ACT competes with the other major college admissions test the SAT Reasoning Test (formerly the "Scholastic Aptitude Test") which is provided by the College Board, Inc.
} 
$56.4 \%$ for graduation in six years) (Chronicle of Higher Education, 2012). These facts both provide the institutional setting for the UMM student population from whom our subjects are drawn, students enrolled at UMM during the 2006-2007 academic year, and also provide some details to flesh out the reasons for the public policy and scientific concern with the factors that affect college success.

\section{Existing literature on the predictors of college success}

\subsection{Literature on personality}

A large research literature exists in the area of educational psychology exploring many characteristics that are associated with high school and college success at US institutions. Here we focus on highlights of research related to college success and the measures we collected from our college student subjects. We start with the Big Five model of personality, which is perhaps the leading psychometric framework used to organize studies of individual behavioral differences that are persistent over time.

The Big Five traits actually make up one level of a hierarchy. There are two highest-level metatraits, Plasticity and Stability, encompassing the Big Five traits or domains, Openness/Intellect and Extraversion under Plasticity, and Conscientiousness, Neuroticism and Agreeableness under Stability. Each of the Big Five traits in turn has two aspects, and each aspect can be further subdivided into multiple facets (DeYoung et al., 2007). Which level is appropriate to associate with specific types of behavioral outcomes depends on the nature and specificity of the behavior in question (DeYoung et al., 2007; Digman, 1997).

In relation to student success, most of the existing research has focused on outcomes such as standardized college admission test scores and grade point averages (GPA). Individuals high in Extraversion might be described as outgoing, talkative, interested in socializing, and sensitive to either the possibility or the attainment of positive rewards and affect, while introverts are the opposite (De Raad and Perugini, 2002; Rustichini et al., 2012). There is some limited evidence suggesting a negative association between extraversion and SAT verbal scores, and a weak negative relationship between extraversion and GPA (Noftle and Robins, 2007). One plausible explanation of this is offered by Komarraju et al. (2009), who link extraversion to extrinsic 
motivation, suggesting students high in this trait may attend college partially for socially-driven rewards.

There is also some limited evidence about Agreeableness and student success. Agreeableness is the tendency towards altruism, concern for, and cooperation with others, while those low in Agreeableness tend to be aggressive and hostile (De Raad and Perugini, 2002; Rustichini et al., 2012). Agreeableness has been found to be negatively associated with lacking motivation (Komarraju et al., 2009), meaning that students high in agreeableness are more likely to be engaged and self-encouraged to learn. Outside of the classroom, agreeable students are more likely to receive higher SAT verbal scores than their peers (Noftle and Robins, 2007).

Neuroticism is the sensitivity to punishment and negative affect, the opposite of emotional stability (De Raad and Perugini, 2002; Rustichini et al., 2012). Individuals high in neuroticism are more likely to have feelings of anxiety and self-consciousness (De Raad and Perugini, 2002). From an academic success perspective, neurotic students may worry to some degree about their personal success (Komarraju et al., 2009). However, there is little evidence of a direct relationship between neuroticism and academic success (Noftle and Robins, 2007; Ridgell and Lounsbury, 2004).

Conscientiousness is characterized by obedience, and self-control, and reflects the ability and tendency to exert control over behavior and impulses in order to follow rules and pursue non-immediate goals (De Raad and Perugini, 2002; Rustichini et al., 2012). Significant evidence suggests these characteristics are beneficial for academic success. Conscientiousness has been found to be a significant predictor of both high school and college GPA (Komarraju et al., 2009; Noftle and Robins, 2007). When predicting final grades in a college course, students high in conscientiousness are more likely to earn top grades than their peers (Lounsbury et al., 2003).

Furthermore, there is evidence that other measures related to Conscientiousness are associated with academic success. Self-discipline has been shown to be positively related to GPA, school attendance, number of hours working on homework, the time of day student begin working on homework, and inversely related to the number of hours students watch TV in a sample of eighth graders (Duckworth and Seligman, 2005). Furthermore, self-discipline was found to be a better predictor of academic success in a future term than IQ, suggesting a lack of diligence may be an explanation for why intelligent students can perform poorly. Grit, a trait 
which includes self-discipline in combination with perseverance, was found to be associated with higher GPA scores (Duckworth et al., 2007). Gritty students at West Point were more likely to complete their rigorous summer training than their less gritty peers. Although self-discipline and grit are not direct measures of conscientiousness, they provide some support for the connection between conscientiousness and academic success.

The last Big Five trait, Openness/Intellect, has two aspects, openness to experience and intellect (DeYoung, 2011). Openness to experience describes interest and engagement in sensory and perceptual information, whereas intellect measures intellectual engagement, abstract reasoning, and understanding of concepts. Intellect is the one trait dimension that is substantially associated with tests of cognitive abilities or cognitive skills (DeYoung, 2011; DeYoung, Quilty, Peterson, \& Gray, 2013). We use a questionnaire measure of the openness aspect of Openness/Intellect, but since we do not have a questionnaire-based measure of the intellect aspect, we instead rely on our three cognitive skill tests to examine the role of cognitive skills in predicting student success.

\subsection{Literature on cognitive skills}

There is a substantial literature on the value of standard measures of cognitive skills in predicting high school and college success. For example, in an examination of the Miller Analogies Test, Kuncel et al. (2004) found strong correlation with Raven's Matrices (our measure of non-verbal IQ) and with several measures of academic success for graduate students. In a study of students in an undergraduate psychology course, (Ridgell and Lounsbury, 2004) showed that general intelligence was a strong predictor of both course grade and overall GPA.

There is also broad evidence that higher ACT and SAT scores, which are both standard measures of high school achievement and college readiness, are associated with increased probability of 6-year graduation; however, most of the predictive power comes from scores in the lower quartile of the distribution. That is, higher scores for weaker students were predictive of higher graduation rates; ACT scores are highly correlated with IQ, and both ACT and IQ measures correlate with graduation (Stumpf and Stanley, 2002).

\section{Design and methods of data collection}

\subsection{Measures collected and protocol}


During the spring semester of 2007 the participants took part in a series of eleven tasks that took two two-hour blocks of time, separated by a short break. Subjects participated in a computer laboratory at UMM with dividers between the computers, and interacted in groups of 25 to 35 at a time. The eight tasks providing measures in the present paper are:

1) Personality profile

2) Incentivized risk aversion experiment

3) Demographic profile

4) Incentivized time preferences experiment

5) Incentivized non-verbal IQ test

6) Incentivized numeracy (quantitative literacy) test

7) Incentivized Hit 15 Points "backward induction" game against the computer

8) Survey on impatience, cooperation, etc.

More detailed description of each task as well as the additional tasks completed by the subjects, are provided in Burks et al. (2008). Here we cover a few points relevant for the present paper.

The personality instrument used was the Multidimensional Personality Questionnaire (MPQ) (Patrick et al., 2002), a standard tool created at the University of Minnesota in 1982. The MPQ has eleven differing scales measuring primary trait dimensions. Because work in economic psychology has moved rather clearly towards a focus on the Big Five as a common psychometric model for personality in the period since our intake data was collected (Almlund et al., 2011; Borghans et al., 2008), we have recast our MPQ results into measurements of the Big Five personality traits, using what is known about the mapping of MPQ scales into Big Five aspects and facets, with some assistance from questions in our impatience and cooperation survey, following Rustichini et al. (2012). Additionally, the mapping from MPQ to Big Five allows us to separate out the proactive, industrious, achievement-oriented aspect of Conscientiousness from the inhibitive, cautious, and orderly aspect.

Although we have no questionnaire measure of Intellect, we do have three tests measuring cognitive skills: non-verbal IQ, numeracy, and the backward induction/planning measure, Hit15. Non-verbal IQ was collected using a computerized adaptation of Raven's Standard Progressive 
Matrices (Raven et al., 2004), an abstract reasoning task. We administered the last four of the five sections, and omitted scores on the last section in calculating results because the standard version of Raven's is intended to be open-ended on time (Raven et al., 2004; p. SPM3), and we had to stop some subjects before they completed the last section. Our measure of numeracy is one half of the two-section adult test of quantitative literacy published by the Educational Testing Service (ETS, 2014), and is designed to measure how well one can use numbers found in ads, forms, flyers, articles or other printed materials, including being able to do appropriate arithmetic operations on the material to infer desired information. Finally, Hit 15 is a game played against the computer, once for training, and then four times for a small monetary prize. The goal is to be the first to add the $15^{\text {th }}$ point to the points total for the game, when each player on each turn must add 1, 2, or 3 points (adding 0 points is not permitted), and with the points total starting out at a different level on each play. This arguably captures not just the willingness to think ahead in the sense of setting goals, but specifically being able to reason backwards from an established goal to decide what action now is best to reach the goal (Gneezy et al., 2010).

We also used incentivized experiments to construct standard measures of two types of economic preferences, those for payments over time, and those for payments under uncertainty. For payments over time we offered four panels of seven questions, each offering a larger future payment versus a smaller and nearer one that decremented in $\$ 5$ jumps (e.g. $\$ 80$ in two days versus $\$ 75$ today). Two panels offered choices between today and a later time, while two offered choices between two days off and a later time. We used this instrument to construct estimates of the quasi-hyperbolic discount rates (Laibson, 1997) for each subject, estimating $\beta$ (Beta), the present-bias parameter, or the discount factor for now versus later, and $\delta$ (Delta), the exponential discount factor for a future date versus a later future date (following Burks et al. (2009) and Burks et al. (2012) for trucker subjects). For choices under uncertainty we offered four panels of six questions, each offering a choice between a dollar payment that incremented and a 50\%-50\% lottery that was kept constant (e.g. get $\$ 2$ for sure or take a 50-50 gamble with $\$ 2$ and $\$ 10$ payoffs); with small monetary gambles such as this risk neutrality is a reasonable benchmark for rational behavior. We used two of these panels (ones with all choices in the positive domain) to estimate a standard risk aversion parameter $\sigma$ (Sigma), with risk aversion increasing in the value of $\sigma$ (thus we made a standard assumption of expected utility with a power utility function with exponent $1-\sigma$, following Burks et al. (2009) for the trucker subjects). 


\subsection{Follow-up data on indicators of success}

Our informed consent agreement gave us the ability to collect indicators of the academic success of our student subjects, which we did after sufficient time had elapsed to allow subjects the opportunity to graduate. We collected final cumulative grade point average (GPA, on a 0.0 to 4.0 scale, with 2.0 required for graduation), and the last date the subject attended UMM (either the date of graduation or of departure). At the time of data collection in spring 2007, the subjects' class standing distribution was as follows: freshmen (first year) 16, sophomores (second year) 30, juniors (third-year) 25, and seniors (final year) 29. Thus in fall, 2013 we were able to update our last date attended information to account for graduation in six years by subjects who were freshmen at intake, in addition to information on graduations that had taken place earlier.

\section{Descriptive statistical summary of subjects by success category}

We divide the student subjects into three groups by their graduation success level: graduated in four years or less $(\mathrm{N}=57)$; graduated in more than four years but no more than six years $(\mathrm{N}=23)$; and other-drop outs who never graduated, transfers, and those who may have graduated in greater than six years $(\mathrm{N}=20)^{7}$

\subsection{Demographics}

Table 2 shows the demographic characteristics of our student subject pool by these success categories, as well as their college admission test scores, and their final cumulative grade point averages at UMM. Since we will later compare our student subjects to our truckers, for comparison we provide parallel statistics on demographics for our trainee trucker sample, also broken out by whether the trainee successfully completed the one year of employment service after training that made the training free by fulfilling the credit contract trainees signed at the start of their residential training program.

\footnotetext{
${ }^{7}$ Because we can't observe students after they leave UMM, we can't be absolutely sure someone who leaves never graduated somewhere, sometime, so more carefully, our graduation categories are all defined as "graduated (from UMM)." However, this is the same framework used by official measures of institutional success and most other academic analyses, because this is typically what is available to researchers.
} 
$<$ INSERT Table 2 ABOUT HERE $>$

Since we observe that there are some statistically significant demographic differences across success groups we will take demographic differences into account as control variables in our multivariate statistical analyses of the predictors of student success.

\subsection{Potential predictors of success}

In Table 3 we list our potential predictors of college graduation success and break out their values by success category for student subjects; for comparison we do the same for our trucker subjects based upon their vocational success. ${ }^{8}$ Each variable is in deviations-from-the-samplemean (z) form, ${ }^{9}$ and the results of rank-sum tests of the differences between the underlying distributions are indicated by the superscripts.

\section{$<$ INSERT Table 3 ABOUT HERE $>$}

We observe that when considered in isolation, several potential predictors show statistically significant differences by success category. Considering cognitive skills, non-verbal IQ is higher among those graduating in four years than either in six years or not at all, Hit15 is higher among those graduating in four years versus those not graduating, while Numeracy shows no statistical differences across success groups. Considering personality traits, the proactive aspect of Conscientiousness is higher among those finishing in four years than those in either lower success category, while Neuroticism is higher among those not graduating than among either higher success category. Finally, Delta is higher (future dollars are discounted less) among those graduating in four years than it is among students in either lower success category.

For comparison, among the truckers all three cognitive skill measures are higher among those who completed their contract. In terms of personality, only one trait is significantly different: the inhibitive aspect of Conscientiousness is lower among those who completed their contract. And both Beta (present bias discount factor) and Delta (general discount factor) have higher values (less present bias and less discounting of the future) among those who completed their contract. Trucker success has been analyzed previously (Burks et al., 2009), and will be discussed below.

\footnotetext{
${ }^{8}$ Note that in Table 3 all success categories are disjoint; this is in contrast to the later regression analyses, in which "Graduated in four years or less" is a proper subset of "Graduated in six years or less."

${ }^{9}$ See Table 8 in the Statistical Appendix, for the means, medians, range, and standard deviation of each underlying variable.
} 


\section{Multivariate analysis of success predictors}

\subsection{Graduation in four years or less}

We next consider how all our predictors fare when we simultaneously account for our demographic control variables and our potential predictors, personality characteristics plus cognitive skills, and economic preferences. Table 4 displays a set of nested logit models predicting whether or not students in our sample graduated in a timely fashion, that is, in four years or less, structured with our demographic controls and the Big Five always included, and varying the cognitive skill measure and the use of economic preferences.

\section{$<$ INSERT Table 4 ABOUT HERE $>$}

We begin with the Big Five. The first thing we observe is that the proactive aspect of Conscientiousness is a robust predictor, with a standard deviation increase doubling or tripling the odds of success by this measure in every specification, with p-values less than 0.01 . This is not inconsistent with prior literature on Conscientiousness and grades (Section 3.1), but distinctively picks out the proactive aspect of this trait as the relevant characteristic for timely graduation. The second thing we observe is that Agreeableness is robustly associated with lower chances of success, with a standard deviation increase cutting the odds of success by this measure by a half to two-thirds, with p-values less than 0.05 . This is unexpected, especially given the existing literature suggesting agreeableness might be positively related to grades (Section 3.1). Since individuals high in Agreeableness are likely to be positively concerned with others, we might conjecture that in our sample, drawn from a population with relatively high social and environmental consciousness, students above the mean in Agreeableness spend too much energy on extra-curricular causes. But this is at best a guess. Neuroticism, which differs across the student success categories in Table 3, does not affect graduation in four years once other variables are taken into account.

Considering our cognitive skills measures, we find that both Hit15 and Non-Verbal IQ have the expected effect, approximately doubling the odds of graduating in four years, with p-values less than 0.05 , when considered alone. Numeracy taken alone has no predictive impact, but this is not surprising as our particular numeracy measure was calibrated for the trucker subject pool, and is not demanding enough to capture very much variation among college students. When all three are entered together, only Hit15 is near statistical significance, at $\mathrm{p}=0.109$. 
Turning to economic preferences, both Beta and Delta, when entered without cognitive skills, have some predictive power. Students who are less present-biased, and those who discount the future over the longer run less, as measured in our experiments with dollar payoffs, are more likely to graduate in four years. Only Delta remains statistically significant in the full model, however.

\subsection{Graduation in six years or less}

Let us compare these findings with those we get when using the same approach to graduation in six years or less. ${ }^{10}$ Table 5 displays a set of nested logit models predicting whether or not students in our sample graduated in six years or less, structured with our demographic controls and the Big Five always included as predictors, and varying the cognitive skill measure and the use of economic preferences.

\section{$<$ INSERT Table 5 ABOUT HERE $>$}

We again begin with the Big Five. The first thing we observe is that the proactive aspect of Conscientiousness is a robust predictor, just as in the case of graduation in four years, but now the odd ratios are even higher, with a standard deviation increase multiplying the odds of success by 3.5 or more times in every specification, and 7.3 times in the full model, with most p-values less than 0.01 . This is a very large effect. We also see the same pattern as before with Agreeableness: a standard deviation increase cuts the odds of success to as little as a quarter of the level before the increase, with all p-values less than 0.05. As with the prior set of results, Neuroticism also fails to predict this outcome when other variables are taken into account.

Cognitive skills show a similar pattern to that observed with graduation in four years, with one big difference: the Hit 15 measure is larger and more significant when entered alone than is Non-Verbal IQ. Further, in the full model, when all our independent variables are competing to provide predictive power, Hit15 remains significant while IQ does not, and a standard deviation increase in Hit15 performance multiplies the odds of success by 2.7 .

Finally, we consider economic preferences. The story here is that there is no story as compared to the prior results - using this larger and more expansive definition of graduation success, differences in economic preferences do not predict differences in graduation. We can

\footnotetext{
${ }^{10}$ Unlike the structure of Table 3, in which success categories are disjoint, here students who graduated in four years are a proper subset of those graduating in six years or less.
} 
offer a natural ex post interpretation based on the academic advising experiences of two of us (Anderson and Burks): a personal characteristic we often observe in advisees who graduate in four years or less is a strong desire to move on to a job or advanced training for a professional career, and a relatively instrumental approach to the collegiate experience. It would not be surprising if students with this approach also had future-oriented time preferences in a measure using monetary rewards.

\subsection{Cumulative GPA}

We next ask what the same modeling approach reveals about predictors of the final cumulative GPA of our student subjects. Table 6 displays a set of nested two-sided Tobit models (to account for the upper and lower bounds on possible GPAs) that predict the GPA at last observation of the students in our sample, structured with our demographic controls and the Big Five always included, and varying the cognitive skill measure and the use of economic preferences.

\section{$<$ INSERT Table 6 ABOUT HERE $>$}

We again begin with the Big Five. The first thing we observe is that the proactive aspect of Conscientiousness is just as robust a predictor of GPA as it was of graduation, with a standard deviation increase predicting a .24 to .28 increase in cumulative GPA (35\% to $40 \%$ of a standard deviation), and with all p-values less than 0.01 . This is consistent with existing literature discussed in Section 3.1. Second, Agreeableness has no predictive power for GPA, in any specification. So whatever the source of its negative effect on graduation, it cannot be due to its effect on GPA.

Cognitive skills also have a positive effect on GPA, as expected from the literature discussed in Section 3.2. The effect sizes are not quite as large as those for the proactive aspect of Conscientiousness, but they are all significant at the 0.05 level. In the full model, when all our independent variables are competing to provide predictive power, all our cognitive skill measures lose statistical significance. This suggests that whatever the source of the positive effect of Hit15 on graduation in six years or less, it does not come through GPA.

Our economic preferences are all significant at the 0.10 level or better when entered alone, and Sigma, the risk aversion parameter, is negatively associated with GPA. However, this 
effect vanishes in the full model, in which only Delta (the long term discount factor) is associated with GPA, suggesting that more future-oriented students tend to have higher GPAs.

\subsection{Comparison with vocational success for trainee truckers}

As mentioned above (Section 1.2), because our study of student success is embedded in a larger project (Burks et al., 2008), we are able to run exactly the same analysis on a group of 1,065 trainee truckers, who were in the middle of a two-week vocational training program at the time of study intake, which took place during December 2005 through August 2006 at a location in the Midwestern US. Each subject had already signed a credit contract that required the trainee to complete the second week of training and a full year of employment after training, in order for the cost of the training program to be absorbed by the motor carrier. Drivers who exited (for any reason) before completing the training and the contracted year of employment owed the market price of the training, in full, to the firm. Table 7 displays a set of nested logit models predicting whether or not a trainee completed the training contract, with the same structure as our student success models: with our demographic controls and the Big Five always included, and varying the cognitive skill measure and the use of economic preferences.

\section{$<$ INSERT Table 7 ABOUT HERE $>$}

We again begin with the Big Five. The first thing we observe is that with the truckers it is not the proactive aspect of Conscientiousness, but the inhibitive aspect that is predictive, and the relationship is inverted: a standard deviation increase in inhibitive Conscientiousness cuts the odds of success by a fifth. The negative role of inhibitive conscientiousness, which is associated with rule-following and self-control, turns out to be due to its effects on quits (as opposed to discharges), and has a natural explanation in an increased reaction to the inability of the driver to control some of the many stochastic factors that affect earnings on the mileage pay (piece rate) system used for road drivers (Rustichini et al., 2012). In some models we see a positive effect of Agreeableness, but this is not robust.

Cognitive skills are all predictive of trucker success. Individually all are highly statistically significant, and have similar effect sizes. But in the full model Hit15 has the largest individual effect, and remains significant at the 0.01 level while Numeracy drops out, and NonVerbal IQ becomes weaker and less statistically significant. We interpret this as due to the importance of reasoning back to the best current action from goals set by the firm to complete 
trips in an environment in which each trip is likely to be unique and effort is subject to multiple, partly conflicting, and partly stochastic constraints (Burks et al., 2009). ${ }^{11}$

Finally, economic preferences have little traction in predicting trucker success. Beta is positively associated with completing the training contract when economic preferences are entered alone, but this disappears in the full model.

\section{Discussion and Conclusions}

We analyzed the power of personality traits, cognitive skills, and economic preferences, controlling for demographic characteristics, to predict three measures of student success for our sample from the University of Minnesota, Morris: graduation in four years or less, graduation in six years or less, and final cumulative GPA. We compared our results to those for predicting success in completing a one year credit contract that made commercial driver training free for trainee truckers who were in a two-week residential training program. Our findings have the following simple summary: the situations in which students studying at a selective four-year undergraduate college, and trainees finishing a two-week vocational training school and then trying to complete a year of employment in a blue-collar service job paid on piece rates, are different in specific and understandable ways, and the characteristics of individual students which predict success in each setting are appropriately different.

Our student subject pool is modest in size, and because not all students were freshman at the time of intake (and even the freshman had already been at UMM for one semester), there may already have been some selection for graduation success in the subject pool. In addition, UMM students occupy a particular location in the demographics of the U.S. higher education industry (as discussed in Section 2.2). While they are in some important ways representative (e.g. they have more typical socio-economic backgrounds for the broad collegiate population than those of students at private liberal arts colleges), we would not suggest that results such as our finding on the negative effect of Agreeableness on graduation, or even our more intuitive result for the proactive aspect of Conscientiousness, are generally applicable without more research.

\footnotetext{
${ }^{11}$ Drivers plan their own trips, which vary from dispatch to dispatch, and which may be for a few hundred or a more than 2,000 miles; they are subject to customer schedule demands, fueling location, parking location, and highway segment restrictions, the Federal hours of service regulations, and traffic and weather conditions.
} 
However, there is one test not usually employed when looking at predictors of success that has a common effect across both settings: the Hit15 "backward induction" task. In this task subjects need to plan ahead not just in the general sense of setting goals (a factor which has been separately studied for its prediction of academic success by psychologists (Morisano et al., 2010)), but in the more specific sense of reasoning backwards from an established goal to the best present action for achieving it. There is in fact a unique solution to the problem as posed in the game, and it appears that the degree to which a subject can solve this puzzle-independently of all the other individual characteristics that we measured - is a strong predictor of eventually achieving graduation for college students. Since it is also a strong predictor of whether vocational trainees can satisfy their training contract and avoid a large financial debt, this result is likely to be more generally applicable, beyond our specific college student subject pool.

Why might this be the case? We offer the following speculation. This measure may be capturing a distinct aspect of the ability to self-manage one's effort in the light of short-tomedium-term goals in a non-routine setting, in which one may have to adjust one's actions due to novel changes in the environment. Among the trucker subjects a factor analysis found that one could combine non-verbal IQ, numeracy, and Hit15 into a common "cognitive skill index."12 Among the students this is not feasible, ${ }^{13}$ but it is nonetheless obvious that Hit 15 requires a form of reasoning and is related to general cognitive ability or IQ. The fact that it provides incremental validity beyond IQ (or numeracy) suggests that it assesses a particular kind of cognitive ability, involving backward induction in the ability to plan, that is not well covered by standard cognitive ability tests. Because there is a "trick" to the instrument we used, it is likely to work well only as long as it is not already known to subjects, but it may be that exploring other ways of capturing a postulated "backward induction" skill could be fruitful, and exploring the value of this measure in other settings could be scientifically valuable.

More directly considering the behavioral economics of education, our findings have clear incremental implications for admissions and retention officials at selective colleges and universities: though the ability to self-manage is already a focus of institutional effort at many

\footnotetext{
${ }^{12}$ Specifically, each component loaded almost equally, and there was one positive eigenvector, indicating one common factor

${ }^{13}$ This is due to not only to the small N, but also to the fact that our measure of numeracy (aimed at high school literacy) is really too low a bar for students at a selective college, and also a weaker limitation that the Standard Progressive Matrices (as opposed to the Advanced Progressive Matrices) provides relatively weak discrimination among subjects near the top end of the scale (Raven et al., 2004)
} 
institutions, it may be that the cognitive skill aspect of this ability is not fully appreciated. Recognizing this might lead to either different admissions policies (assuming a valid instrument for measuring the backward induction component of planning ability were available), or perhaps more naturally, to the development of supplemental interventions aimed at developing this skill among students who are not moving effectively towards graduation. 


\section{Statistical Appendix}

Table 8 provides the underlying descriptive statistics for the independent variables utilized, including the means and standard deviation values used to construct the $\mathrm{z}$-score versions of these variables.

$<$ INSERT Table 8 ABOUT HERE $>$ 


\begin{tabular}{|c|c|c|c|}
\hline \multicolumn{5}{|c|}{ Table 1: ACT Rankings of Colleges by Selectivity } \\
$\begin{array}{c}\text { Selectivity } \\
\text { Level }\end{array}$ & $\begin{array}{c}\text { ACT } \\
\text { Middle } \\
\mathbf{5 0 \%}\end{array}$ & $\begin{array}{c}\text { SAT } \\
\text { Middle } \\
\mathbf{5 0 \%}\end{array}$ & \multicolumn{1}{c|}{ Definition } \\
\hline $\begin{array}{c}\text { 1. Highly } \\
\text { Selective }\end{array}$ & $25-30$ & $1710-2000$ & Majority admitted from top 10\% of H.S. class \\
\hline 2. Selective & $21-26$ & $1470-1770$ & Majority admitted from top 25\% of H.S. class \\
\hline 3. Traditional & $18-24$ & $1290-1650$ & Majority admitted from top 50\% of H.S. class \\
\hline 4. Liberal & $17-22$ & $1230-1530$ & Majority admitted from bottom 50\% of H.S. \\
\hline class
\end{tabular}




\begin{tabular}{|c||c|c|c|c|c||}
\hline & \multicolumn{3}{|c|}{ Students } & \multicolumn{2}{c|}{ Truckers } \\
\hline & $\begin{array}{c}\text { 4 Year } \\
\text { Grad }\end{array}$ & Year Grad & Other & $\begin{array}{c}\text { Completed } \\
1 \text { year }\end{array}$ & $\begin{array}{c}\text { Did not } \\
\text { Complete }\end{array}$ \\
\hline N & 57 & 23 & 20 & 358 & 711 \\
\hline Age & 20.58 & $21.96^{\mathrm{a}}$ & $20.53^{\mathrm{a}}$ & 37.55 & 37.11 \\
\hline Gender (\%Male) & 38.6 & 39.1 & 40 & 89.2 & 90.2 \\
\hline $\begin{array}{c}\text { Family Income } \\
\text { (thousands of \$) }\end{array}$ & $84.2^{\mathrm{ab}}$ & $68.7^{\mathrm{a}}$ & $68.5^{\mathrm{b}}$ & 22.8 & 23.8 \\
\hline Race (\%White) & $82.5^{\mathrm{a}}$ & $91.3^{\mathrm{b}}$ & $45.0^{\mathrm{ab}}$ & $86.0^{\mathrm{a}}$ & $77.2^{\mathrm{a}}$ \\
\hline ACT (z) & $0.24^{\mathrm{a}}$ & $0.11^{\mathrm{b}}$ & $-0.82^{\mathrm{ab}}$ & N/A & N/A \\
\hline UMM GPA (raw) & $3.41^{\mathrm{a}}$ & $3.12^{\mathrm{b}}$ & $2.66^{\mathrm{ab}}$ & N/A & N/A \\
\hline UMM GPA (z) & $0.37^{\mathrm{ab}}$ & $-0.13^{\mathrm{ac}}$ & $-0.91^{\mathrm{bc}}$ & N/A & N/A \\
\hline
\end{tabular}

Table 2: Student ACT and GPA, and Demographics for Both Subject Groups, by Success Category: The values for Age and Family Income are means. Gender and Race reported as percentages. Variables with "(z)" are in sample standard deviation units from the sample mean (within each subject pool). Columns with the same superscript are from statistically distinct sample distributions (within each subject pool); bold superscript letters represent $\mathrm{p} \leq .05$ and regular superscript letters represent $\mathrm{p} \leq .10$. Mean values are compared using two-sided rank sum tests and percentages are compared using two-sided tests of differences in proportions. 


\begin{tabular}{|c|c|c|c|c|c|}
\hline & \multicolumn{3}{|c|}{ Students } & \multicolumn{2}{|c|}{ Truckers } \\
\hline & 4 Year & 6 Year & Other & $\begin{array}{c}\text { Completed } 1 \\
\text { Year }\end{array}$ & $\begin{array}{c}\text { Did not } \\
\text { Complete }\end{array}$ \\
\hline $\mathbf{N}$ & 57 & 23 & 20 & 358 & 711 \\
\hline IQ (mean=100) & $102.0^{\mathrm{ab}}$ & $97.6^{b}$ & $97.15^{\mathrm{a}}$ & $102.1^{\mathrm{a}}$ & $98.9^{\mathrm{a}}$ \\
\hline IQ (z) & $0.20^{\mathbf{a b}}$ & $-0.24^{\mathrm{a}}$ & $-0.28^{\mathbf{b}}$ & $0.21^{\mathrm{a}}$ & $-0.11^{\mathrm{a}}$ \\
\hline Hit15 (z) & $0.18^{\mathrm{a}}$ & 0.07 & $-0.61^{\mathrm{a}}$ & $0.29^{\mathrm{a}}$ & $-0.11^{a}$ \\
\hline Numeracy (z) & 0.01 & 0.22 & -0.3 & $0.20^{\mathrm{a}}$ & $-.10^{\mathrm{a}}$ \\
\hline Agreeableness (z) & -0.1 & 0.2 & 0.05 & 0.02 & -0.01 \\
\hline ConscInhibitive (z) & 0.07 & -0.26 & 0.09 & $-0.12^{\mathrm{a}}$ & $0.06^{\mathrm{a}}$ \\
\hline ConscProactive (z) & $0.24^{\mathrm{ab}}$ & $-0.17^{a}$ & $-0.47^{\mathbf{b}}$ & -0.06 & 0.03 \\
\hline Extraversion (z) & -0.27 & 0.24 & -0.21 & 0.00 & 0.00 \\
\hline Neuroticism (z) & $-0.01^{\mathrm{a}}$ & $-0.32^{b}$ & $0.39^{\mathrm{ab}}$ & 0.00 & 0.00 \\
\hline Openness (z) & 0.05 & -0.15 & 0.04 & -0.01 & 0.03 \\
\hline Beta $(z)$ & 0.26 & -0.28 & -0.45 & $0.12^{a}$ & $-0.06^{\mathbf{a}}$ \\
\hline Delta (z) & $0.23^{\mathbf{a b}}$ & $-0.29^{\mathrm{a}}$ & $-0.36^{\mathbf{b}}$ & $0.07^{\mathrm{a}}$ & $-0.03^{\mathrm{a}}$ \\
\hline Sigma (z) & -0.03 & 0.16 & -0.13 & -0.05 & 0.02 \\
\hline
\end{tabular}

Table 3: Potential Predictors of Success among Students \& Truckers, by Success Category: Variables with "(z)" are in sample standard deviation units from the sample mean (within each subject pool). Columns with the same superscript are from statistically distinct sample distributions (within each subject pool); bold superscript letters represent $\mathrm{p} \leq .05$ and regular superscript letters represent $\mathrm{p} \leq .10$. Mean values are compared using the two-sided rank sum test. 


\begin{tabular}{|c|c|c|c|c|c|c|}
\hline & Big 5 & $\begin{array}{l}\text { Big } 5 \text { W/ } \\
\text { Hit15 }\end{array}$ & $\begin{array}{cc}\text { Big } 5 & W / \\
\text { IQ } & \end{array}$ & $\begin{array}{l}\text { Big } 5 \text { W/ } \\
\text { Num }\end{array}$ & $\begin{array}{l}\text { Big } 5 \text { W/ } \\
\text { Econ }\end{array}$ & Full \\
\hline Variable: & $\mathrm{OR} / \mathrm{p}$ & $\mathrm{OR} / \mathrm{p}$ & $\mathrm{OR} / \mathrm{p}$ & $\mathrm{OR} / \mathrm{p}$ & $\mathrm{OR} / \mathrm{p}$ & $\mathrm{OR} / \mathrm{p}$ \\
\hline \multirow[t]{2}{*}{ Age } & 0.894 & 0.859 & 0.918 & 0.881 & 0.849 & 0.849 \\
\hline & $(0.408)$ & $(0.366)$ & $(0.588)$ & $(0.385)$ & $(0.318)$ & $(0.408)$ \\
\hline \multirow[t]{2}{*}{ Race(Non-White) } & $0.388^{*}$ & 0.401 & 0.424 & $0.368^{*}$ & 0.537 & 0.508 \\
\hline & $(0.092)$ & $(0.126)$ & $(0.131)$ & $(0.079)$ & $(0.333)$ & $(0.321)$ \\
\hline \multirow[t]{2}{*}{ Gender } & 0.794 & 0.988 & 0.780 & 0.850 & $0.315^{*}$ & 0.438 \\
\hline & $(0.661)$ & $(0.983)$ & $(0.645)$ & $(0.758)$ & $(0.084)$ & $(0.229)$ \\
\hline \multirow[t]{2}{*}{ Income } & 1.007 & 1.007 & 1.004 & 1.008 & 1.000 & 0.998 \\
\hline & $(0.276)$ & $(0.307)$ & $(0.585)$ & $(0.240)$ & $(0.986)$ & $(0.846)$ \\
\hline \multirow[t]{2}{*}{ Agreeableness } & $0.474 * *$ & $0.435 * *$ & $0.457 * *$ & $0.461 * *$ & $0.413 * *$ & $0.346 * * *$ \\
\hline & $(0.017)$ & $(0.013)$ & $(0.013)$ & $(0.016)$ & $(0.016)$ & $(0.008)$ \\
\hline \multirow[t]{2}{*}{ ConscInhibitive } & 1.300 & 1.375 & 1.031 & 1.325 & 1.309 & 1.517 \\
\hline & $(0.399)$ & $(0.332)$ & $(0.930)$ & $(0.389)$ & $(0.463)$ & $(0.342)$ \\
\hline \multirow[t]{2}{*}{ ConsProactive } & $2.228 * * *$ & $2.404 * * *$ & $2.789 * * *$ & $2.118 * *$ & $3.105 * * *$ & $3.313 * * *$ \\
\hline & $(0.008)$ & $(0.006)$ & $(0.002)$ & $(0.014)$ & $(0.002)$ & $(0.003)$ \\
\hline \multirow[t]{2}{*}{ Extraversion } & 0.668 & 0.735 & 0.698 & 0.697 & 0.641 & 0.706 \\
\hline & $(0.137)$ & $(0.268)$ & $(0.194)$ & $(0.188)$ & $(0.169)$ & $(0.292)$ \\
\hline \multirow[t]{2}{*}{ Neuroticism } & 0.882 & 0.982 & 0.940 & 0.850 & 0.794 & 0.751 \\
\hline & $(0.647)$ & $(0.948)$ & $(0.822)$ & $(0.579)$ & $(0.446)$ & $(0.392)$ \\
\hline \multirow[t]{2}{*}{ Openness } & 1.289 & 1.226 & 1.255 & 1.271 & 1.398 & 1.356 \\
\hline & $(0.328)$ & $(0.436)$ & $(0.395)$ & $(0.360)$ & $(0.241)$ & $(0.307)$ \\
\hline \multirow[t]{2}{*}{ Hit15 } & & $2.036 * *$ & & & & 1.708 \\
\hline & & $(0.020)$ & & & & $(0.109)$ \\
\hline \multirow[t]{2}{*}{ IQ } & & & $1.881 * *$ & & & 1.208 \\
\hline & & & $(0.025)$ & & & $(0.602)$ \\
\hline \multirow[t]{2}{*}{ Numeracy } & & & & 0.945 & & 0.683 \\
\hline & & & & $(0.824)$ & & $(0.243)$ \\
\hline \multirow[t]{2}{*}{ Beta } & & & & & $1.737^{*}$ & 1.676 \\
\hline & & & & & $(0.091)$ & $(0.168)$ \\
\hline \multirow[t]{2}{*}{ Delta } & & & & & $2.274 * *$ & $2.086^{* *}$ \\
\hline & & & & & $(0.013)$ & $(0.031)$ \\
\hline \multirow[t]{2}{*}{ Sigma } & & & & & 0.894 & 0.912 \\
\hline & & & & & $(0.661)$ & $(0.739)$ \\
\hline \multirow[t]{2}{*}{ Constant } & 12.150 & 24.344 & 9.113 & 15.507 & 115.062 & 112.829 \\
\hline & $(0.381)$ & $(0.360)$ & $(0.504)$ & $(0.366)$ & $(0.185)$ & $(0.264)$ \\
\hline $\mathbf{N}$ & 100 & 100 & 100 & 99 & 97 & 96 \\
\hline pseudo R-sq & 0.164 & 0.213 & 0.202 & 0.165 & 0.274 & 0.308 \\
\hline$* \mathrm{p}<0.1$ & $* * * \mathrm{p}$ & & & & & \\
\hline
\end{tabular}

Table 4: Nested Models Predicting Graduation in 4 years. All variables except demographics are in $\mathrm{z}$ form (sample standard deviation units from the sample mean, by subject pool); coefficients are in odds ratio form (each estimated value multiplies the odds of a subject being in the success category being modeled, so $x<1.00$ reduces odds, $x=1.00$ means no effect, and $x>1.00$ increases odds); p-values are below each estimated odds ratio. Ns reflect the number of subjects with complete data. 


\begin{tabular}{|c|c|c|c|c|c|c|}
\hline & Big 5 & $\begin{array}{c}\text { Big 5 } \\
\text { W/ Hit15 }\end{array}$ & $\begin{array}{l}\text { Big } 5 \\
\text { W/ IQ }\end{array}$ & $\begin{array}{c}\text { Big } 5 \\
\text { W/ Num }\end{array}$ & $\begin{array}{c}\text { Big } 5 \\
\text { W/ Econ }\end{array}$ & Full \\
\hline Variables: & $\mathrm{OR} / \mathrm{p}$ & $\mathrm{OR} / \mathrm{p}$ & $\mathrm{OR} / \mathrm{p}$ & $\mathrm{OR} / \mathrm{p}$ & $\mathrm{OR} / \mathrm{p}$ & $\mathrm{OR} / \mathrm{p}$ \\
\hline \multirow[t]{2}{*}{ Age } & 1.386 & 1.321 & 1.451 & 1.286 & 1.444 & 1.269 \\
\hline & $(0.183)$ & $(0.280)$ & $(0.145)$ & $(0.311)$ & $(0.223)$ & $(0.407)$ \\
\hline \multirow[t]{2}{*}{ Race(Non-White) } & $0.075 * * *$ & $0.048 * * *$ & $0.074 * * *$ & $0.063 * * *$ & $0.092 * * *$ & $0.059 * * *$ \\
\hline & $(0.001)$ & $(0.001)$ & $(0.001)$ & $(0.001)$ & $(0.003)$ & $(0.004)$ \\
\hline \multirow[t]{2}{*}{ Gender } & 1.011 & 1.889 & 1.179 & 1.345 & 0.821 & 1.833 \\
\hline & $(0.988)$ & $(0.447)$ & $(0.827)$ & $(0.699)$ & $(0.813)$ & $(0.562)$ \\
\hline \multirow[t]{2}{*}{ Income } & 0.993 & 0.988 & 0.986 & 0.995 & 0.985 & 0.980 \\
\hline & $(0.465)$ & $(0.270)$ & $(0.201)$ & $(0.659)$ & $(0.192)$ & $(0.134)$ \\
\hline \multirow[t]{2}{*}{ Agreeableness } & $0.350 * *$ & $0.237 * *$ & $0.370 * *$ & $0.318^{* *}$ & $0.344 * *$ & $0.244 * *$ \\
\hline & $(0.034)$ & $(0.016)$ & $(0.034)$ & $(0.032)$ & $(0.035)$ & $(0.025)$ \\
\hline \multirow[t]{2}{*}{ ConscInhibitive } & 0.850 & 0.943 & 0.528 & 0.749 & 0.745 & 0.557 \\
\hline & $(0.706)$ & $(0.903)$ & $(0.183)$ & $(0.543)$ & $(0.533)$ & $(0.351)$ \\
\hline \multirow[t]{2}{*}{ ConsProactive } & $3.587 * * *$ & $5.159 * * *$ & $6.020 * * *$ & $3.183 * *$ & $4.466 * * *$ & $7.340 * * *$ \\
\hline & $(0.009)$ & $(0.004)$ & $(0.002)$ & $(0.021)$ & $(0.009)$ & $(0.009)$ \\
\hline \multirow{2}{*}{ Extraversion } & 0.957 & 1.166 & 1.090 & 1.036 & 0.695 & 0.936 \\
\hline & $(0.904)$ & $(0.693)$ & $(0.821)$ & $(0.926)$ & $(0.398)$ & $(0.883)$ \\
\hline \multirow[t]{2}{*}{ Neuroticism } & 0.699 & 0.830 & 0.800 & 0.738 & 0.627 & 0.686 \\
\hline & $(0.308)$ & $(0.626)$ & $(0.553)$ & $(0.439)$ & $(0.237)$ & $(0.448)$ \\
\hline \multirow{2}{*}{ Openness } & 1.120 & 0.967 & 1.059 & 1.028 & 1.177 & 0.965 \\
\hline & $(0.746)$ & $(0.927)$ & $(0.873)$ & $(0.942)$ & $(0.645)$ & $(0.932)$ \\
\hline \multirow[t]{2}{*}{ Hit15 } & & $3.153 * * *$ & & & & $2.741 * *$ \\
\hline & & $(0.009)$ & & & & $(0.043)$ \\
\hline \multirow[t]{2}{*}{ IQ } & & & $2.668 * *$ & & & 1.974 \\
\hline & & & $(0.014)$ & & & $(0.204)$ \\
\hline \multirow[t]{2}{*}{ Numeracy } & & & & 1.279 & & 1.028 \\
\hline & & & & $(0.465)$ & & $(0.945)$ \\
\hline \multirow[t]{2}{*}{ Beta } & & & & & 1.512 & 1.130 \\
\hline & & & & & $(0.215)$ & $(0.787)$ \\
\hline \multirow[t]{2}{*}{ Delta } & & & & & 1.522 & 1.979 \\
\hline & & & & & $(0.276)$ & $(0.126)$ \\
\hline \multirow[t]{2}{*}{ Sigma } & & & & & 0.957 & 1.407 \\
\hline & & & & & $(0.903)$ & $(0.500)$ \\
\hline \multirow[t]{2}{*}{ Constant } & 0.028 & 0.109 & 0.021 & 0.112 & 0.031 & 0.818 \\
\hline & $(0.464)$ & $(0.664)$ & $(0.445)$ & $(0.658)$ & $(0.563)$ & $(0.712)$ \\
\hline $\mathbf{N}$ & 100 & 100 & 100 & 99 & 97 & 96 \\
\hline pseudo R-sq & 0.270 & 0.371 & 0.334 & 0.300 & 0.309 & 0.428 \\
\hline$* \mathrm{p}<0.1 \quad * * \mathrm{p}<0.05$ & $* * * \mathrm{p}<0.01$ & & & & & \\
\hline
\end{tabular}

Table 5: Nested Models Predicting Graduation in Six Years. All variables except demographics are in $\mathrm{z}$ form (sample standard deviation units from the sample mean, by subject pool); coefficients are in odds ratio form (each estimated value multiplies the odds of a subject being in the success category being modeled, so $x<1.00$ reduces odds, $x=1.00$ means no effect, and $x>$ 1.00 increases odds); $p$-values are below each estimated odds ratio. Ns reflect the number of subjects with complete data. 


\begin{tabular}{|c|c|c|c|c|c|}
\hline & $\begin{array}{c}\text { Big } 5 \\
\text { W/ Hit15 }\end{array}$ & $\begin{array}{c}\text { Big } 5 \\
\text { W/ IQ }\end{array}$ & $\begin{array}{c}\text { Big } 5 \\
\text { W/ Num }\end{array}$ & $\begin{array}{c}\text { Big } 5 \\
\text { W/ Econ }\end{array}$ & Full \\
\hline & $\mathrm{b} / \mathrm{p}$ & $\mathrm{b} / \mathrm{p}$ & $\mathrm{b} / \mathrm{p}$ & $\mathrm{b} / \mathrm{p}$ & $\mathrm{b} / \mathrm{p}$ \\
\hline \multirow[t]{2}{*}{ Age } & -0.021 & -0.002 & -0.027 & -0.033 & -0.025 \\
\hline & $(0.330)$ & $(0.916)$ & $(0.227)$ & $(0.123)$ & $(0.251)$ \\
\hline \multirow[t]{2}{*}{ Race(Non-White) } & -0.017 & -0.019 & -0.041 & 0.008 & 0.023 \\
\hline & $(0.894)$ & $(0.881)$ & $(0.748)$ & $(0.946)$ & $(0.843)$ \\
\hline \multirow[t]{2}{*}{ Gender } & 0.080 & 0.042 & 0.060 & -0.164 & -0.081 \\
\hline & $(0.497)$ & $(0.714)$ & $(0.614)$ & $(0.172)$ & $(0.492)$ \\
\hline \multirow[t]{2}{*}{ Income } & $0.002 *$ & 0.001 & $0.003 * *$ & 0.001 & 0.001 \\
\hline & $(0.094)$ & $(0.389)$ & $(0.046)$ & $(0.660)$ & $(0.538)$ \\
\hline \multirow{2}{*}{ Agreeableness } & 0.019 & 0.020 & 0.036 & 0.046 & 0.036 \\
\hline & $(0.756)$ & $(0.740)$ & $(0.576)$ & $(0.444)$ & $(0.532)$ \\
\hline \multirow{2}{*}{ ConscInhibitive } & 0.106 & 0.013 & 0.054 & 0.078 & 0.035 \\
\hline & $(0.124)$ & $(0.857)$ & $(0.447)$ & $(0.236)$ & $(0.622)$ \\
\hline \multirow[t]{2}{*}{ ConsProactive } & $0.189 * * *$ & $0.241 * * *$ & $0.169 * * *$ & $0.199 * * *$ & $0.214^{* * *}$ \\
\hline & $(0.003)$ & $(0.000)$ & $(0.009)$ & $(0.001)$ & $(0.001)$ \\
\hline \multirow[t]{2}{*}{ Extraversion } & 0.058 & 0.055 & 0.040 & 0.082 & 0.094 \\
\hline & $(0.343)$ & $(0.355)$ & $(0.523)$ & $(0.187)$ & $(0.121)$ \\
\hline \multirow[t]{2}{*}{ Neuroticism } & 0.016 & 0.013 & 0.027 & -0.017 & 0.021 \\
\hline & $(0.792)$ & $(0.830)$ & $(0.680)$ & $(0.771)$ & $(0.719)$ \\
\hline \multirow[t]{2}{*}{ Openness } & -0.033 & -0.039 & -0.031 & -0.012 & -0.032 \\
\hline & $(0.578)$ & $(0.500)$ & $(0.598)$ & $(0.832)$ & $(0.549)$ \\
\hline \multirow[t]{2}{*}{ Hit15 } & $0.152 * * *$ & & & & 0.074 \\
\hline & $(0.006)$ & & & & $(0.175)$ \\
\hline \multirow[t]{2}{*}{ IQ } & & $0.200 * * *$ & & & 0.079 \\
\hline & & $(0.001)$ & & & $(0.198)$ \\
\hline \multirow[t]{2}{*}{ Numeracy } & & & $0.116 * *$ & & 0.050 \\
\hline & & & $(0.040)$ & & $(0.358)$ \\
\hline \multirow[t]{2}{*}{ Beta } & & & & $0.180 * * *$ & $0.126 * *$ \\
\hline & & & & $(0.002)$ & $(0.044)$ \\
\hline \multirow[t]{2}{*}{ Delta } & & & & $0.117^{* *}$ & $0.112 * *$ \\
\hline & & & & $(0.045)$ & $(0.048)$ \\
\hline \multirow[t]{2}{*}{ Sigma } & & & & -0.057 & -0.040 \\
\hline & & & & $(0.273)$ & $(0.419)$ \\
\hline \multirow[t]{2}{*}{ constant } & $3.409 * * *$ & $3.130 * * *$ & $3.512 * * *$ & $3.938^{* * *}$ & $3.703 * * *$ \\
\hline & $(0.000)$ & $(0.000)$ & $(0.000)$ & $(0.000)$ & $(0.000)$ \\
\hline $\mathbf{N}$ & 100 & 100 & 99 & 97 & 96 \\
\hline Adj R-sq & 0.193 & 0.215 & 0.175 & 0.254 & 0.296 \\
\hline$* \mathrm{p}<0.1 \quad * * \mathrm{p}<0.05$ & $* * * \mathrm{p}<0.01$ & & & & \\
\hline
\end{tabular}

Table 6: Nested Models Predicting Final Student Cumulative GPA. All variables except demographics are in $\mathrm{z}$ form (sample standard deviation units from the sample mean, by subject pool); coefficients are in odds ratio form (each estimated value multiplies the odds of a subject being in the success category being modeled, so $x<1.00$ reduces odds, $x=1.00$ means no effect, and $x>1.00$ increases odds); p-values are below each estimated odds ratio. Ns reflect the number of subjects with complete data. 


\begin{tabular}{|c|c|c|c|c|c|c|}
\hline & Big 5 & $\begin{array}{c}\text { Big } 5 \\
\text { W/ Hit15 }\end{array}$ & $\begin{array}{l}\text { Big } 5 \\
\text { W/ IQ }\end{array}$ & $\begin{array}{c}\text { Big } 5 \\
\text { W/ Num }\end{array}$ & $\begin{array}{c}\text { Big } 5 \\
\text { W/ Econ }\end{array}$ & Full \\
\hline Variable & $\mathrm{OR} / \mathrm{p}$ & $\mathrm{OR} / \mathrm{p}$ & $\mathrm{OR} / \mathrm{p}$ & $\mathrm{OR} / \mathrm{p}$ & $\mathrm{OR} / \mathrm{p}$ & $\mathrm{OR} / \mathrm{p}$ \\
\hline \multirow[t]{2}{*}{ Age } & 1.001 & 1.000 & 1.007 & 1.001 & 1.001 & 1.004 \\
\hline & $(0.902)$ & $(0.980)$ & $(0.349)$ & $(0.897)$ & $(0.869)$ & $(0.613)$ \\
\hline \multirow[t]{2}{*}{ Race(Non-White) } & 0.874 & 0.701 & 0.858 & 0.899 & 0.870 & 0.739 \\
\hline & $(0.640)$ & $(0.309)$ & $(0.633)$ & $(0.714)$ & $(0.628)$ & $(0.391)$ \\
\hline \multirow[t]{2}{*}{ Gender } & 0.858 & 0.941 & 0.832 & 0.842 & 0.841 & 0.889 \\
\hline & $(0.496)$ & $(0.803)$ & $(0.428)$ & $(0.445)$ & $(0.443)$ & $(0.633)$ \\
\hline \multirow[t]{2}{*}{ Income } & 0.997 & 0.995 & 0.998 & 0.997 & 0.997 & 0.995 \\
\hline & $(0.357)$ & $(0.117)$ & $(0.461)$ & $(0.394)$ & $(0.327)$ & $(0.125)$ \\
\hline \multirow[t]{2}{*}{ Agreeableness } & $1.146^{*}$ & $1.200^{*}$ & 1.140 & 1.131 & 1.135 & 1.163 \\
\hline & $(0.099)$ & $(0.052)$ & $(0.128)$ & $(0.139)$ & $(0.128)$ & $(0.111)$ \\
\hline \multirow[t]{2}{*}{ ConscInhibitive } & $0.803 * * *$ & $0.857^{*}$ & $0.819 * *$ & $0.824 * *$ & $0.811 * * *$ & 0.871 \\
\hline & $(0.004)$ & $(0.070)$ & $(0.012)$ & $(0.012)$ & $(0.007)$ & $(0.110)$ \\
\hline \multirow[t]{2}{*}{ ConsProactive } & 0.932 & 0.971 & 0.967 & 0.926 & 0.918 & 0.977 \\
\hline & $(0.377)$ & $(0.741)$ & $(0.688)$ & $(0.342)$ & $(0.292)$ & $(0.794)$ \\
\hline \multirow{2}{*}{ Extraversion } & 1.009 & 1.018 & 0.987 & 1.023 & 1.012 & 1.019 \\
\hline & $(0.909)$ & $(0.827)$ & $(0.860)$ & $(0.761)$ & $(0.868)$ & $(0.816)$ \\
\hline \multirow[t]{2}{*}{ Neuroticism } & 0.954 & 1.033 & 1.003 & 0.976 & 0.939 & 1.027 \\
\hline & $(0.575)$ & $(0.729)$ & $(0.971)$ & $(0.777)$ & $(0.466)$ & $(0.782)$ \\
\hline \multirow[t]{2}{*}{ Openness } & 1.040 & 0.994 & 1.037 & 1.029 & 1.040 & 0.987 \\
\hline & $(0.577)$ & $(0.943)$ & $(0.615)$ & $(0.688)$ & $(0.579)$ & $(0.868)$ \\
\hline \multirow[t]{2}{*}{ Hit15 } & & $1.398 * * *$ & & & & $1.300 * * *$ \\
\hline & & $(0.000)$ & & & & $(0.004)$ \\
\hline \multirow[t]{2}{*}{ IQ } & & & $1.416^{* * *}$ & & & $1.197^{*}$ \\
\hline & & & $(0.000)$ & & & $(0.062)$ \\
\hline \multirow[t]{2}{*}{ Numeracy } & & & & $1.312 * * *$ & & 1.010 \\
\hline & & & & $(0.000)$ & & $(0.922)$ \\
\hline \multirow[t]{2}{*}{ Beta } & & & & & $1.187 * *$ & 1.151 \\
\hline & & & & & $(0.029)$ & $(0.123)$ \\
\hline \multirow[t]{2}{*}{ Delta } & & & & & 0.999 & 0.946 \\
\hline & & & & & $(0.993)$ & $(0.516)$ \\
\hline \multirow[t]{2}{*}{ Sigma } & & & & & 0.956 & 0.960 \\
\hline & & & & & $(0.521)$ & $(0.607)$ \\
\hline \multirow[t]{2}{*}{ constant } & $0.536^{* *}$ & $0.553 * *$ & $0.412 * * *$ & $0.525^{* *}$ & $0.530 * *$ & $0.470 * *$ \\
\hline & $(0.016)$ & $(0.046)$ & $(0.002)$ & $(0.013)$ & $(0.016)$ & $(0.015)$ \\
\hline $\mathbf{N}$ & 1033 & 860 & 981 & 1033 & 1027 & 855 \\
\hline pseudo R-sq & 0.010 & 0.026 & 0.026 & 0.022 & 0.015 & 0.034 \\
\hline$* \mathrm{p}<0.1 \quad * * \mathrm{p}<0.05$ & $* * * p<0.01$ & & & & & \\
\hline
\end{tabular}

Table 7: Nested Models Predicting Trucker Success. All variables except demographics are in z form (sample standard deviation units from the sample mean, by subject pool); coefficients are in odds ratio form (each estimated value multiplies the odds of a subject being in the success category being modeled, so $x<1.00$ reduces odds, $x=1.00$ means no effect, and $x>1.00$ increases odds); p-values are below each estimated odds ratio. Ns reflect the number of subjects with complete data, and are reduced when Hit15 is included due to an initial programming error. 


\begin{tabular}{|c|c|c|c|c|c|c|c|c|c|c|}
\hline \multirow[b]{2}{*}{ Variable: } & \multicolumn{5}{|c|}{ Students } & \multicolumn{5}{|c|}{ Truckers } \\
\hline & Mean & Median & $\mathrm{SD}$ & $\min$ & $\max$ & Mean & Median & SD & $\min$ & $\max$ \\
\hline IQ & 100.0 & 100.7 & $\begin{array}{c}10.0 \\
0\end{array}$ & 67.91 & 111.6 & 100.0 & 102.1 & 10.00 & 48.25 & 114.1 \\
\hline Hit 15 & 3.51 & 4.00 & 0.76 & 0.00 & 4.00 & 2.43 & 3.00 & 1.25 & 0.0 & 4.00 \\
\hline Numeracy & 10.19 & 10.00 & 1.50 & 6.00 & 12.00 & 8.45 & 9.00 & 2.57 & 0.0 & 12.00 \\
\hline Agreeableness & 24.02 & 24.50 & 5.59 & 9.00 & 35.00 & 26.77 & 28.00 & 5.73 & 5.0 & 36.00 \\
\hline Consc Inhibitive & 14.04 & 14.00 & 2.37 & 7.00 & 19.00 & 15.16 & 15.00 & 2.18 & 5.0 & 20.00 \\
\hline Consc Proactive & 17.00 & 17.00 & 3.39 & 8.00 & 25.00 & 20.50 & 20.00 & 3.27 & 8.0 & 28.00 \\
\hline Extraversion & 65.29 & 64.50 & 8.06 & 39.00 & 81.00 & 60.54 & 61.00 & 8.84 & 30.0 & 93.00 \\
\hline Neuroticism & 29.53 & 29.00 & 6.18 & 13.00 & 43.00 & 26.09 & 25.00 & 5.95 & 12.0 & 46.00 \\
\hline Openness & 29.91 & 30.00 & 4.76 & 20.00 & 43.00 & 27.46 & 28.00 & 4.87 & 13.0 & 44.00 \\
\hline Beta & 0.97 & 1.00 & 0.06 & 0.72 & 1.07 & 0.90 & 0.95 & 0.13 & 0.56 & 1.07 \\
\hline Delta & 0.99 & 1.00 & 0.01 & 0.98 & 1.00 & 0.99 & 0.99 & 0.01 & 0.98 & 1.00 \\
\hline Sigma & 0.56 & 0.63 & 0.73 & -1.35 & 3.90 & 0.39 & 0.28 & 1.65 & -1.35 & 6.00 \\
\hline ACT & 26.22 & 27.00 & 3.40 & 16.00 & 34.00 & N/A & $\mathrm{N} / \mathrm{A}$ & $\mathrm{N} / \mathrm{A}$ & N/A & $\mathrm{N} / \mathrm{A}$ \\
\hline UMM GPA & 3.19 & 3.23 & 0.59 & 0.96 & 4.00 & N/A & N/A & N/A & N/A & N/A \\
\hline
\end{tabular}

Table 8: Means and Standard Deviations of Potential Predictors. The mean, median, standard deviation, minimum, and maximum within each sample (i.e. by subject pool). 


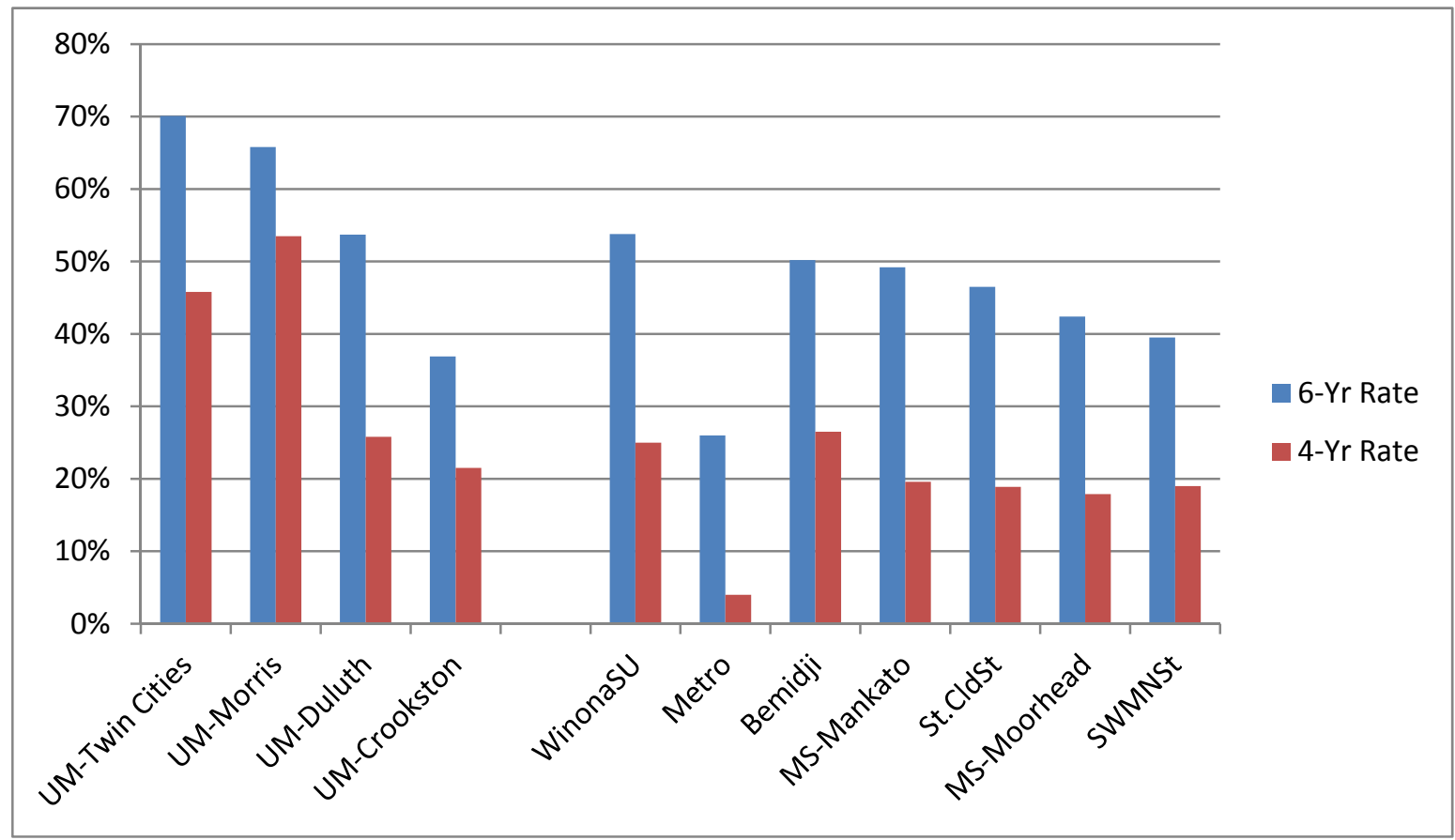

Figure 1: 4-Year and 6-Year Graduation Rates at MN Public Four-Year Institutions. Shows the graduation rates of freshman classes enrolled at each of the publicly funded colleges or universities in Minnesota (2010 data). Data source: Chronicle of Higher Education. 


\section{References}

ACT, 2013, National Collegiate Retention and Persistence to Degree Rates: 2012 Data. ACT, Inc., Iowa City, Iowa.

Adams, C., 2011, Colleges Try to Unlock Secrets to Student Retention. Education Digest. Prakken Publications, pp. 19-23.

Almlund, M., Duckworth, A.L., Heckman, J., Kautz, T., 2011, Chapter 1 - Personality Psychology and Economics. In: S.M. Eric A. Hanushek, W. Ludger (Eds.). Handbook of the Economics of Education. Elsevier, pp. 1-181.

Borghans, L., Duckworth, A.L., Heckman, J.J., Weel, B.t., 2008. The Economics and Psychology of Personality Traits. Journal of Human Resources, 43(4), 972-1059.

Burks, S., Carpenter, J., Götte, L., Monaco, K., Porter, K., Rustichini, A., 2008, Using Behavioral Economic Field Experiments at a Firm: the Context and Design of the Truckers and Turnover Project. In: S. Bender, J. Lane, K. Shaw, F. Andersson, T. von Wachter (Eds.). The Analysis of Firms and Employees: Quantitative and Qualitative Approaches. NBER and University of Chicago Chicago and London, pp. 45-106.

Burks, S., Carpenter, J., Götte, L., Rustichini, A., 2012. Which measures of time preference best predict outcomes: Evidence from a large-scale field experiment. Journal of Economic Behavior and Organization, 84(1), 308-320.

Burks, S.V., Carpenter, J., Götte, L., Rustichini, A., 2009. Cognitive Skills Affect Economic Preferences, Social Awareness, and Job Attachment. Proceedings of the National Academy of Science (USA), 106(19), 7745-7750.

Carnegie Foundation for the Advancement of Teaching, 2010, All-Inclusive Classification for the University of Minnesota-Morris. Carneige Foundation for the Advancement of Teaching.

Chronicle of Higher Education, 2012, Graduation Rates for All Colleges in Minnesota, 2010. Chronicle of Higher Education.

Chronicle of Higher Education, 2014, Minnesota public colleges (4-year). College Completion: Who graduates from college, who doesn't, and why it matters. Chronicle.com.

De Raad, B., Perugini, M. (Eds.), 2002. Big Five Assessment. Hogrefe \& Huber Publishers, Ashland, $\mathrm{OH}$.

DeYoung, C.G., 2011, Intelligence and Personality. In: R.J. Sternberg, S.B. Kaufman (Eds.). The Cambridge Handbook of Intelligence. Cambridge Handbooks in Psychology. Cambridge Univeristy Press, New York, pp. 711-737.

DeYoung, C.G., Quilty, L.C., Peterson, J.B., 2007. Between facets and domains: 10 aspects of the big five. Journal of Personality and Social Psychology, 93(5), 880-896.

Digman, J.M., 1997. Higher-order factors of the big five. Journal of Personality and Social Psychology, 73(6), 1246-1256.

Duckworth, A.L., Peterson, C., Matthews, M.D., Kelly, D.R., 2007. Grit: Perseverance and passion for long-term goals. Journal of Personality and Social Psychology, 92(6), 10871101.

Duckworth, A.L., Seligman, M.E.P., 2005. Self-discipline outdoes IQ in predicting academic performance of adolescents. Psychological Science, 16(12), 939-944.

ETS, 2014, Types of Literacy: Prose, Document, Quantitative, and Health Skills. Educational Testing Service, Inc, Princeton, NJ.

Gneezy, U., Rustichini, A., Vostroknutov, A., 2010. Experience and Insight in the Race Game. Journal of Economic Behavior and Organization, 75(2), 144-155. 
Henrich, J., Heine, S.J., Norenzayan, A., 2010. The weirdest people in the world? Behavioral and Brain Sciences, 33(2/3), 1-75.

Horn, A.S., 2013. Effectiveness and Efficiency in Promoting Timely Degree Completion: A Performance Rating System for the States, Midwestern Higher Education Compact, Minneapolis, MN.

Komarraju, M., Karau, S.J., Schmeck, R.R., 2009. Role of the big five personality traits in predicting college students' academic motivation and achievement. Learning and Individual Differences, 19(1), 47-52.

Kuncel, N.R., Hezlett, S.A., Ones, D.S., 2004. Academic Performance, Career Potential, Creativity, and Job Performance: Can One Construct Predict Them All? Journal of Personality and Social Psychology, 86(1), 148-161.

Laibson, D., 1997. Golden Eggs and Hyperbolic Discounting. Quarterly Journal of Economics, $112(2), 443-477$.

Leonhardt, D., 2005. The College Dropout Boom. (Cover story). New York Times, 154(53224), A1-A15.

Lounsbury, J.W., Sundstrom, E., Loveland, J.M., Gibson, L.W., 2003. Intelligence, "Big Five" personality traits, and work drive as predictors of course grade. Personality and Individual Differences, 35(6), 1231-1239.

Morisano, D., Hirsh, J.B., Peterson, J.B., Pihl, R.O., Shore, B.M., 2010. Setting, elaborating, and reflecting on personal goals improves academic performance. Journal of Applied Psychology, 95(2), 255-264.

National Center for Higher Education Management Systems, 2010. Closing the Postsecondary Attainment Gap: Midwestern Competitiveness in a Global Economy, Midwestern Higher Education Compact, Minneapolis, MN.

Noftle, E.E., Robins, R.W., 2007. Personality predictors of academic outcomes: Big five correlates of GPA and SAT scores. Journal of Personality and Social Psychology, 93(1), 116-130.

Patrick, C., Curtin, J., Tellegen, A., 2002. Development and Validation of a Brief Form of the Multidimensional Personality Questionnaire. Psychological Assessment, 14(2), 150-164.

Raven, J., Raven, J.C., Court, J.H., 2004, Raven Manual Section 3: The Standard Progressive Matrices. Manual for Raven's Progressive Matrices and Vocabulary Scales. Psychological Corporation, San Antonio, TX.

Ridgell, S.D., Lounsbury, J.W., 2004. Predicting Academic Success: General Intelligence, "Big Five" Personality Traits, and Work Drive. College Student Journal, 38(4), 607-619.

Rustichini, A., DeYoung, C., Anderson, J., Burks, S., 2012. Toward the Integration of Personality Theory and Decision Theory in the Explanation of Economic and Health Behavior. Institute for the Study of Labor (IZA) Discussion Papers(\#6750).

Snyder, T.D., Dillow, S.A., 2013, Digest of Education Statistics, 2012. NCES.

Stratton, L.S., O’Toole, D.M., Wetzel, J.N., 2008. A multinomial logit model of college stopout and dropout behavior. Economics of Education Review, 27(3), 319-331.

Stumpf, H., Stanley, J.C., 2002. Group data on high school grade point averages and scores on academic aptitude tests as predictors of institutional graduation rates. Educational and Psychological Measurement, 62(6), 1042-1052. 